\title{
Characterization of natural pozzolan-based geopolymeric binders
}

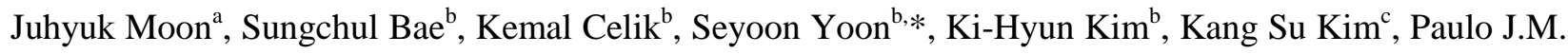
Monteiro ${ }^{\mathrm{b}}$

${ }^{a}$ Civil Engineering Program, Department of Mechanical Engineering, Stony Brook University, NY 11794, USA

${ }^{\mathrm{b}}$ Department of Civil and Environmental Engineering, University of California, Berkeley, CA 94720, USA

${ }^{\mathrm{c}}$ Department of Architectural Engineering, University of Seoul, 90 Jeonnong-dong, Dongdaemun-gu, Seoul 130-743, Korea

* Corresponding author. E-mail address: yoonseyoon@gmail.com

Keywords: Basaltic ash, Natural Pozzolan, Geopolymer, Compressive strength

\begin{abstract}
Properties and characteristics of fly ash- or slag-based geopolymers have been extensively explored but comparatively less information is available for natural pozzolan-based geopolymers. The present work focuses on microstructural characteristics of natural pozzolan-based geopolymers activated by sodium hydroxide and a mixture of sodium hydroxide and sodium silicate. Synchrotron XRD and SEM-EDS studies combined with compressive strength tests successfully demonstrate the feasibility of the use of natural pozzolan for sustainable construction material. It is concluded that the geopolymers have sufficient strength as structural materials and matrices contain C-S-H like crystal as well as zeolites of hydroxysodalite and zeolite Y. Two zeolites of hydroxysodalite and zeolite Y are found as the main activation products in sodium hydroxide activation. Substitution with sodium silicate solution yields higher compressive strength and a denser microstructure with dominant activation products of $\mathrm{C}-\mathrm{S}-\mathrm{H}$ like crystal, zeolite $\mathrm{Y}$, and phillipsite. It has been proposed that the crystal size of the activation products ranges from $10 \mathrm{~nm}$ to $1 \mu \mathrm{m}$. Different microstructural characteristics found herein provide a valuable information to develop natural pozzolan-based sustainable structural materials with improved properties.
\end{abstract}




\section{Introduction}

Natural pozzolans (also known as volcanic pozzolan) have been widely used as substitutes for portland cement, because of the advantages of cost reduction and increased durability [1-3]. Natural pozzolan in cement enhances the ultimate compressive strengths by producing additional calcium-silicatehydrates $(\mathrm{C}-\mathrm{S}-\mathrm{H})$ and reduces the heat of hydration which is particularly useful in massive-scale construction. Furthermore, the environmental impact of the production of conventional cement offers a new merit to natural pozzolan as a supplementary cementitious material. For instance, natural basaltic pozzolan from Saudi Arabia has been reported as a possible replacement of 25 mass\% portland cement [4]. Portland cement-based ternary and quaternary blends containing fly ash, silica fume, blast-furnace slag, and natural pozzolans can also be utilized by optimizing their mixing proportions [5].

On the other hand, geopolymers have emerged as a new promising alternative for ordinary Portland cement. Not only it has lower environmental impact but it also has advantages of high compressive strength, low shrinkage, fast setting, and low thermal conductivity [6-8]. Considerable research have been done to investigate the possibility of utilizing various industrial by-products and natural raw materials for the production of geopolymer cements. Aluminosilicate materials including granulated blast-furnace slag and fly ash and calcined natural mineral of kaolinite have been reported as possible candidates for the geopolymer production. The fundamental properties and structural characteristics of geopolymers derived from fly ash, slag, and metakaolin have been investigated regarding raw material selection, solution types, curing conditions, and resulting microstructures [7-9]. When the aluminosilicate raw materials are activated by alkalis, complex chemical and physical reactions result in the formation of geopolymer. The structure of main binding matrix in geopolymer is known to be similar to synthetic or natural crystalline zeolites but it is mostly amorphous [7, 10-12].

Although natural pozzolans are also aluminosilicate materials, the use of natural pozzolans as a geopolymer was recently reported. Alkali-activated Taftan pozzolan in Iran was found to be suitable for construction applications $[13,14]$. A mixture of sodium hydroxide and waterglass produced the formation of a geopolymer binder with appropriate workability. As subsequent research on geopolymerization of the Taftan pozzolan, the effect of various curing conditions and engineering properties of geopolymer concrete were investigated for practical applications [15, 16]. In addition, the effect of mineral additives including kaolinite, lime, and slag $[17,18]$ and heat treatment on Taftan pozzolan [19] were lately studied. However, the reactive components of the pozzolan and associated hydration products have not been described in detail. 
As a supplementary material for Portland cement, the mechanism of natural pozzolan in concrete is well understood, which can be explained as so-called pozzolanic reaction [1-3, 20, 21]. However, the use of natural pozzolan as a full cement replacement is still being explored. Especially, previous study on geopolymerization of natural pozzolan is only limited to one case of Taftan addesite from Iran [14, 17, 22]. The present work describes the potential use of natural volcanic pozzolan from Saudi Arabia as a construction material for the production of geopolymer cements. Since this new type of alkali-activated geopolymer cement will have different chemistry from fly ash- or slag-based geopolymer, microstructural characterization is vital to understand mechanical behavior, durability, and binding characteristics of the gel with aggregates. This work, therefore, examines the properties of alkali-activated natural pozzolanbased geopolymers by focusing on the microstructure using high-resolution synchrotron X-ray diffraction (XRD), scanning electron microscopy (SEM) with energy-dispersive X-ray spectroscopy (EDS), and compressive strength tests.

\section{Experimental methods}

\subsection{Materials}

Natural pozzolanic material from basalt fields in the Kingdom of Saudi Arabia was used in this study. During strombolian-type volcanic explosions, numerous pyroclastic cones with basaltic lava fields were formed in Harrats, Saudi Arabia. Although the basaltic ash deposits are widespread in the Harrats, a few industrial applications of it have been reported. One of the applications is used as a lightweight coarse aggregate [23]. The pozzolan also satisfies the requirements of ASTM C618 for Class N natural pozzolan for supplementary cementitious materials [24-26]. Bulk density, specific gravity, and absorption properties of it were previously investigated [26, 27]. Petrographic and XRD studies found a gel-palagonite as the most abundant component and other crystals of forsterite, anorthite, and diopside as minor phases [27]. The bulk chemical composition of the natural pozzolan was determined using a Phillips X-ray fluorescence (XRF) spectrometer and is given in Table 1. The natural pozzolan has more $\mathrm{Ca}$ content (i.e., $\mathrm{CaO} 8.78$ mass\%) than typical Class F fly ash but it is less than Class $\mathrm{C}$ fly ash. Particle size distribution of ground natural pozzolan is shown in Fig. 1 [27].

\subsection{Sample preparation}


The ground raw materials were activated with $10 \mathrm{M}$ analytical grade sodium hydroxide solution (SH) (Fisher Scientific, S318-1) and a mixture of 80 mass\% of sodium hydroxide solution and 20 mass\% of sodium silicate solution ( $\mathrm{SH} / \mathrm{WG}$ ) (PQ Corporation, $\mathrm{N}^{\circledR} 38$, also known as waterglass). The provided mass ratios are $\mathrm{SiO}_{2} / \mathrm{Na}_{2} \mathrm{O}=3.22$, mass $\%$ of $\mathrm{Na}_{2} \mathrm{O}=8.2$, mass $\%$ of $\mathrm{SiO}_{2}=26.4$, and mass $\%$ of $\mathrm{H}_{2} \mathrm{O}=$ 65.4. The solution to binder (s/b) ratio was kept as 0.45 . Curing condition of $80{ }^{\circ} \mathrm{C}$ and $100 \% \mathrm{RH}$ was selected. In cases of fly ash- and slag-based geopolymer, the geopolymer binder is known to be synthesized in a temperature range of $20 \sim 90{ }^{\circ} \mathrm{C}$. More amorphous phases are expected at low temperature and more crystalline at higher temperature [6]. As a feasibility study, $80{ }^{\circ} \mathrm{C}$ and $100 \% \mathrm{RH}$ were chosen for enhanced characterization of activation products. All samples were cast in cylindrical molds of $\phi 2.54 \mathrm{~cm} \times 2.54 \mathrm{~cm}$. Summary of the mixture proportion is presented in Table 2 .

\subsection{Experimental methods}

The samples cured for 1, 3, 7, and 28 days were chosen for compressive strength tests. The compressive strength tests on three identical samples were performed using a Baldwin universal testing machine and the averaged results are shown in Fig. 2 with error bars. Synchrotron XRD has widely been applied to cementitious materials to characterize crystalline or amorphous components under various conditions [28-31]. The high flux of photon energy from synchrotron allows to obtain diffraction peaks in ordinary 2 theta range as well as in small-angle range with a high resolution (i.e., high peak intensity with less noise and lower background) [32,33]. The high-resolution XRD patterns were collected from beamline 12.2.2 at the Advanced Light Source, Lawrence Berkeley National Laboratory [34] using a wavelength of $\lambda=0.6199 \AA$ and sample-to-detector distance of $322.513 \mathrm{~mm}$. Ethanol was used to stop the hydration process at 1, 3, 7, and 28 days. All samples including raw natural pozzolan were air-dried and ground into fine powder for the XRD measurement. Collected two dimensional diffraction patterns from a MAR345 image plate were integrated to one dimensional patterns. Last, SEM analysis for chemical compositions and micro-scale images was performed using ZEISS EVO®MA10. 28 days-cured samples of NP-SH and NP-SH/WG were polished and epoxy-impregnated before carbon-coating for back scattered images (BSE) and energy dispersive X-ray (EDS) chemical analysis.

\section{Results and discussion}

\subsection{Compressive strength}


The compressive strength development for samples is shown in Fig. 2. In the presence of sodium hydroxide, the addition of sodium silicate significantly increased compressive strength. The measured 28 days strength of $33 \mathrm{MPa}(\mathrm{NP}-\mathrm{SH})$ and $47 \mathrm{MPa}(\mathrm{NP}-\mathrm{SH} / \mathrm{WG})$ are suitable for most of the structural applications. Figs. 3 presents typical microstructures of $\mathrm{NP}+\mathrm{SH}$ and $\mathrm{NP}+\mathrm{SH} / \mathrm{WG}$, indicating the $\mathrm{NP}+\mathrm{SH}$ sample has more porous microstructure. In order to determine the micro-size pore distributions, the porosities of the samples were obtained from SEM images according to image analysis techniques [35, 36]. For averaged quantification, 10 BSE images $(500 \times)$ on each samples were randomly selected. With Image Processing Toolbox ${ }^{\mathrm{TM}} 7$ in Matlab, the original BSE images were converted to mibary images using s threshold value of 0.32 . The pore connectivity of a value 4 was selected to define individual pores in the each binary images (i.e., pore-segmentation command in the toolbox [37]). The result of the image processing analysis is shown in Fig. 4. The decreased porosity is evident in the NP-SH/WG sample and this result is consistent with compressive strength tests. It can be easily drawn from the Figs. 2-4 that dense microstructure with lower micro-porosity (especially less pores ranging 1-10 $\mu \mathrm{m}$ ) increased the compressive strength.

In geopolymer science, the addition of soluble silicates accelerates the reaction and enhances compressive strength by creating more long-chain silicate oligomers [7, 8]. In addition, it has been suggested that the sodium silicate can lower the energy barrier of the initial reaction for geopolymerization $[38,39]$. In the case of natural pozzolan-based geopolymer paste, the type of activation solution is found to be also critical in the development of geopolymerization. While the NPSH/WG sample has a dense microstructure, NP-SH has cavities inside the remnant pozzolans as well as in geopolymeric matrices. Thus, more soluble silicates with alkali solution seem to reflect the faster geopolymerization (higher strength at early ages) and fill the space with denser activation products. Detail characterization on activation products is achieved through high-resolution XRD experiments.

\subsection{High-resolution $X$-ray diffraction}

The XRD patterns for raw material and samples cured for 1, 3, 7, and 28 days are shown in Figs. 5 and 6. In raw basaltic pozzolan, amorphous hump at around 2-5 $\AA$ was observed and it rapidly disappeared in 1 day geopolymerization process. The similar amorphous humps were observed in fly ash [12] and in natural pozzolan [27]. The hump in natural pozzolan may indicate the amorphous silica [12] and/or gel-palagonite [25, 27]. Minor crystalline phases in the pozzolan are anorthite $\left(\mathrm{CaAl}_{2} \mathrm{Si}_{2} \mathrm{O}_{8}\right.$, peak positions from [27]), maghemite $\left(\gamma-\mathrm{Fe}_{2} \mathrm{O}_{3}, \mathrm{ICSD} \# 44517\right)$, forsterite $\left(\mathrm{Mg}_{2} \mathrm{SiO}_{4}\right.$, peak positions from [27]), brookite $\left(\mathrm{TiO}_{2}, \mathrm{ICSD} \# 88380\right)$, cristobalite alpha $\left(\mathrm{SiO}_{2}, \mathrm{ICSD} \# 77456\right)$, and diopside $\left(\mathrm{MgCaSi}_{2} \mathrm{O}_{6}\right.$, peak 
positions from [27]). Among them, anorthitic plagioclass, forsteritic olivine, and diopsidic clinopyroxene were also confirmed in previous study on the same basaltic pozzolan by laboratory-based XRD test [27]. From the high-resolution XRD, reactive components in raw materials and small amount of reaction products can be more accurately detectable with clearer XRD peak profiles than the laboratory-based XRD [40, 41]. The result for natural pozzolans is shown in Figs. 5 and 6. The amorphous material was rapidly consumed and new strong peaks appeared in 1 day-cured samples. Based on the observation, it can be drawn that amorphous phase, maghemite, and cristobalite alpha are highly reactive, whereas anorthite has moderate reactivity with alkaline solution.

Significant quantities of zeolites were formed in both NP-SH and NP-SH/WG samples. It has been well known that geopolymeric gel has similar atomic structure with several zeolites but the quick reaction of fly ash with alkaline solution results in amorphous or semi-crystalline $[6,11,42]$. The crystalline zeolites of phillipsite, hydroxysodalite, chabazite, and Na-P1 (gismondine) were generally found in slag- and fly ash-based geopolymer pastes [11, 42-45]. As shown in Fig. 5, zeolite Y $\left(\left(\mathrm{Na}_{2}, \mathrm{Ca}, \mathrm{Mg}\right)_{3.5}\left(\mathrm{Al}_{7} \mathrm{Si}_{17} \mathrm{O}_{48}\right) \cdot 32 \mathrm{H}_{2} \mathrm{O}\right.$, JCPDS \#38-0239) and hydroxysodalite $\left(\mathrm{Na}_{8}\left(\mathrm{AlSiO}_{4}\right)_{6}(\mathrm{OH})_{2} \cdot 2 \mathrm{H}_{2} \mathrm{O}\right.$, JCPDS \#11-0401) were found as main activation products in NP-SH sample. Interestingly, new zeolite of phillipsite ((Ca, $\left.\mathrm{Na}_{2}, \mathrm{~K}_{2}\right)_{3} \mathrm{Al}_{6} \mathrm{Si}_{10} \mathrm{O}_{32} \cdot 12 \mathrm{H}_{2} \mathrm{O}$, JCPDS \#46-1427) and C-S-H like crystal (JCPDS \#34-0002) were additionally found in NP-SH/WG sample along with a small amount of zeolite Y (Fig. 6). Since there was no calcium hydroxide found, the formation of the C-S-H like crystal is not from the pozzolanic reaction. Hydrotalcite $\left(\mathrm{Mg}_{6} \mathrm{Al}_{2} \mathrm{CO}_{3}(\mathrm{OH})_{16} \cdot 4\left(\mathrm{H}_{2} \mathrm{O}\right)\right)$, a core activation product of slag-based geopolymer, was not observed in both samples. This can confirm the low reactivity of diopside $\left(\mathrm{MgCaSi}_{2} \mathrm{O}_{6}\right)$ and forsterite $\left(\mathrm{Mg}_{2} \mathrm{SiO}_{4}\right)$ under alkali activation.

Although no distinct basal peaks of C-S-H or zeolite Y were observed in NP-SH specimen, twodimensional XRD pattern (shown in Fig. 7) indicates very weak basal peaks of C-S-H like crystal and zeolite Y. Long-range amorphous phases in the alkali-activated natural pozzolan seem to prevent the clear intensity of them in integrated XRD pattern in Fig. 5. This proves the high-resolution synchrotronbased XRD can be a useful technique for identification of complex geopolymer binders especially containing amorphous components. While C-S-H is a main reaction product in slag-based geopolymer, several studies report the co-existence of C-S-H and geopolymeric gel in fly ash-based geopolymer [8, 11, $42,44]$. It has been suggested that Ca content in raw fly ash is an important factor to determine the formation of C-S-H which will enhance the strength of geopolymer paste. In this study, the C-S-H like crystal was found in both samples despite a small amount of $\mathrm{Ca}$ in raw basaltic pozzolan $(8.8$ mass\% $\mathrm{CaO}$, Table 1). Furthermore, the addition of sodium silicate accelerated the formation of C-S-H like crystal. Thus it can be suggested that additional silicates and sodium ions from sodium silicate play an essential 
role in the formation of C-S-H in which the Ca in the C-S-H might have been substituted with Na and/or $\mathrm{Al}[46]$.

The sodium silicate in the presence of sodium hydroxide not only accelerated the formation of zeolite $\mathrm{Y}$ and C-S-H like crystals but changed the structural type of final product. The phillipsite was only produced in NP-SH/WG while hydroxysodalite was only observed in NP-SH system. This finding indicates that dissolved $\mathrm{Al}$ and $\mathrm{Si}$ ions from basaltic natural pozzolan prefer to produce not hydroxysodalites but phillipsites when sodium silicate solution is added. Together with the phillipsite crystal, it can be concluded that more crystalline products of C-S-H and zeolite Y play a key role in the formation of dense microstructure and the improvement of compressive strength. However, amorphous components in both samples, which should have also influenced the microstructure [47], were still challenging to be qualitatively analyzed through the high-resolution XRD.

\subsection{SEM-EDS analysis}

Microstructural images $(1,500 \times)$ of NP-SH and NP-SH/WG are shown in Figs. 8 and 9. Again, porous microstructure can explain lower compressive strength of NP-SH. It is interesting to note that most of large-size cavities $(5-10 \mu \mathrm{m})$ in Fig. 8 were inside the remnant grains of the pozzolan. This suggests that weakened remnant particles might also affect the lower strength of NP-SH sample. This SEM-EDS analysis frequently identified unreacted particles of diopside as well as anorthite whose low reactivity was previously confirmed by XRD study in section 3.2.

Calcite is a common mineral in basaltic ash [27, 48]. While it was not detected by XRD analysis, one unreacted calcite was observed as a minor phase in NP-SH sample (Fig. 8(a)). In both samples, we found cracked rims around gel-palagonite (Figs. 8(b), 9(b), and 9(d)). In previous study on high-volume basaltic pozzolan-based cement mixture, it was proposed that the rims around the gel-palagonite prevented or delayed pozzolanic reaction [27]. In this study, the rims also seem to prevent the geopolymerization but cracking on the rims might give an evidence of slow chemical reaction of the rims with alkaline solution. However, it is not clear that the cracks were from the chemical reaction or from any mechanical instability caused by drying condition. In addition, gel-palagonite (i.e., amorphous in XRD) was often found in both 28 days-cured samples (Figs. 8(b), 8(c), 9(b), and 9(d)). Since the amorphous hump in raw material disappeared rapidly, the remaining micro-sized gel-palagonites suggest the large part of the disappeared hump is not from gel-palagonite but probably from amorphous silica [12]. 
The chemical compositions of 28 days-cured samples are plotted in atomic ratio in Figs. 10 and 11. The $\mathrm{Al} / \mathrm{Si}$ ratios of matrices considerably vary (0.2-0.7) whereas the ratios of gel-palagonite rims do not (0.1-0.3). In addition, the rims and matrices have higher atomic ratio of $[\mathrm{Na}+\mathrm{K}+\mathrm{Mg}+\mathrm{Ca}+\mathrm{Fe}]=0.2-$ 1.4, while the ratios of remnant pozzolans (marked in yellow) are less than 0.6 in both samples. These compositions reflect the incorporation of dissolved species of $\mathrm{Na}, \mathrm{K}, \mathrm{Mg}, \mathrm{Ca}$ or $\mathrm{Fe}$ in matrices through geopolymerization process [27]. The narrower range of the value for NP-SH/WG (0.4-1.0) than NP-SH (0.2-1.4) might indicate more standardized incorporation of those species.

Table 3 provides averaged atomic compositions for a series of selected spots in matrices. The averaged $\mathrm{Si} / \mathrm{Al}$ ratios are 2.01 for NP-SH and 2.31 for NP-SH/WG, respectively, with standard geopolymer having 1.79 to 2 [6, 12]. However, as shown in Figs. 10-11, the Si/Al ratios of matrices significantly vary in alkali-activated natural pozzolan systems. There is less variation of $[\mathrm{Na}+\mathrm{K}] / \mathrm{Al}$ in NP-SH/WG than in NP-SH (Fig. 13) but substantial variation in the ratio is typical in geopolymer matrices $[6,12]$.

Lastly, C-S-H like crystal and zeolites which were identified through XRD analysis, were not individually detected in SEM-EDS analysis. For a Bragg reflection to be observed, about 10 ordered lattices have to be repeated. Considering the lattice parameter of the crystals $(\sim 10 \AA)$, the minimum crystal size has to be larger than $10 \mathrm{~nm}$ for XRD detectable. On the other hand, the electron beam size of EDS spot analysis is about $1 \mu \mathrm{m}$. Therefore, it can be proposed that matrices are composed of main activation crystals (i.e., C-S-H like crystal and zeolites), whose crystal size is $10 \mathrm{~nm}-1 \mu \mathrm{m}$. This is the consistent result with previously reported nanometer size of zeolites in fly ash-based geopolymer [49].

\section{Conclusions}

The results from the investigation of basaltic natural pozzolan-based geopolymer for the full replacement of ordinary cement allowed concluding that:

Naturally abundant basaltic pozzolan from Saudi Arabia can be used for construction materials through geopolymerization process. The compressive strength of the natural pozzolan-based geopolymers was found to be suitable for construction applications. Amorphous phase, maghemite, and cristobalite alpha in the pozzolan shows high reactivity under alkaline solution.

The significant factor affecting the microstructure of geopolymer pastes is the type of activator. It is clear that the 20 mass\% substitution of sodium hydroxide with sodium silicate has a positive effect 
on the compressive strength. Reduced micro-size porosity and more activation products of phillipsite and C-S-H like crystal enhanced the compressive strength of the geopolymer pastes.

When raw basaltic pozzolans were activated with sodium hydroxide solution, zeolite crystals of hydroxysodalite and zeolite Y and C-S-H like crystal were observed regardless of adding sodium silicate solution. The matrices consist of amorphous geopolymeric gel and the crystals whose crystal size ranged from $10 \mathrm{~nm}$ to $1 \mu \mathrm{m}$ (i.e., detectable in XRD but not in SEM-EDS).

Zeolite crystal of phillipsite was observed as one of the main products in sodium silicate added activation but it was not observed without the sodium silicate. The sodium silicate solution also accelerated the hydration of C-S-H like crystal and zeolite Y, suggesting that more crystalline phases yield less porosity and higher compressive strength. These findings are giving new perspectives for general geopolymer science, but it also requires further systematic investigation to understand the formation mechanism of phillipsite and the role of various zeolite crystals in macroscopic properties of geopolymer.

\section{Acknowledgments}

This research was funded by Award No. KUS-11-004021, from King Abdullah University of Science and Technology. The Advanced Light Source is supported by the Director, Office of Science, Office of Basic Energy Sciences, of the U.S. Department of Energy under No. DE-AC02-05CH11231.

\section{References}

[1] Uzal B, Turanli L, Mehta PK. High-volume natural pozzolan concrete for structural applications. ACI Materials Journal. 2007;104(5).

[2] Papadakis V, Tsimas S. Supplementary cementing materials in concrete: Part I: efficiency and design. Cement and Concrete Research. 2002;32(10):1525-32.

[3] Rodríguez-Camacho R, Uribe-Afif R. Importance of using the natural pozzolans on concrete durability. Cement and concrete research. 2002;32(12):1851-8.

[4] Khan M, Alhozaimy A. Properties of natural pozzolan and its potential utilization in environmental friendly concrete. Canadian Journal of Civil Engineering. 2010;38(1):71-8.

[5] Pipilikaki P, Katsioti M. Study of the hydration process of quaternary blended cements and durability of the produced mortars and concretes. Construction and Building Materials. 2009;23(6):2246-50.

[6] Khale D, Chaudhary R. Mechanism of geopolymerization and factors influencing its development: a review. Journal of Materials Science. 2007;42(3):729-46.

[7] Duxson P, Fernández-Jiménez A, Provis J, Lukey G, Palomo A, Van Deventer J. Geopolymer technology: the current state of the art. Journal of Materials Science. 2007;42(9):2917-33. 
[8] Xu H, Van Deventer J. The geopolymerisation of alumino-silicate minerals. International Journal of Mineral Processing. 2000;59(3):247-66.

[9] Xu H, van Deventer JS. Effect of source materials on geopolymerization. Industrial \& engineering chemistry research. 2003;42(8):1698-706.

[10] Davidovits J. Geopolymers. Journal of Thermal Analysis and calorimetry. 1991;37(8):1633-56.

[11] Oh JE, Monteiro PJ, Jun SS, Choi S, Clark SM. The evolution of strength and crystalline phases for alkali-activated ground blast furnace slag and fly ash-based geopolymers. Cement and Concrete Research. 2010;40(2):189-96.

[12] Phair J, Van Deventer J. Characterization of fly-ash-based geopolymeric binders activated with sodium aluminate. Industrial \& engineering chemistry research. 2002;41(17):4242-51.

[13] Allahverdi A, Mehrpour K, Kani EN. Taftan pozzolan-based geopolymer cement. IUST International Journal of Engineering Science. 2008;19(3):1-5.

[14] Allahverdi A, Mehrpour K, Kani EN. Investigating the possibility of utilizing pumice-type natural pozzonal in production of geopolymer cement. CERAMICS SILIKATY. 2008;52(1):16.

[15] Kani EN, Allahverdi A. Effects of curing time and temperature on strength development of inorganic polymeric binder based on natural pozzolan. Journal of materials science. 2009;44(12):3088-97.

[16] Bondar D, Lynsdale CJ, Milestone NB, Hassani N, Ramezanianpour AA. Engineering properties of alkali-activated natural pozzolan concrete. ACI Materials Journal. 2011;108(1).

[17] Bondar D, Lynsdale C, Milestone N, Hassani N, Ramezanianpour A. Effect of adding mineral additives to alkali-activated natural pozzolan paste. Construction and Building Materials.

2011;25(6):2906-10.

[18] Allahverdi A, Kani EN, Yazdanipour M. Effects of blast-furnace slag on natural pozzolan-based geopolymer cement. Ceramics-Silikaty. 2011;55(1):68-78.

[19] Bondar D, Lynsdale C, Milestone N, Hassani N, Ramezanianpour A. Effect of heat treatment on reactivity-strength of alkali-activated natural pozzolans. Construction and Building Materials.

2011;25(10):4065-71.

[20] Jackson MD, Chae SR, Mulcahy SR, Meral C, Taylor R, Li P, et al. Unlocking the secrets of Altobermorite in Roman seawater concrete. Am Mineral. 2013;98.

[21] Jackson MD, Moon J, Gotti E, Taylor R, Chae SR, Kunz M, et al. Material and Elastic Properties of Al-Tobermorite in Ancient Roman Seawater Concrete. Journal of the American Ceramic Society. 2013.

[22] Bondar D, Lynsdale C, Milestone NB, Hassani N, Ramezanianpour A. Effect of type, form, and dosage of activators on strength of alkali-activated natural pozzolans. Cement and Concrete Composites.

2011;33(2):251-60.

[23] Hossain K. Properties of volcanic scoria based lightweight concrete. Magazine of Concrete Research. 2004;56(2):111-20.

[24] Roobol M, Pint J, Al-Shanti M, AL-JUAID A, Al-Amoudi S, Pint S. Preliminary survey for lava-tube caves on Harrat Kishb. Kingdom of Saudi Arabia, Saudi Geological Survey Open-File Report SGS-OF-2002-

3. 2002.

[25] Moufti M, Sabtan A, El-Mahdy O, Shehata W. Assessment of the industrial utilization of scoria materials in central Harrat Rahat, Saudi Arabia. Engineering geology. 2000;57(3):155-62.

[26] Sabtan A, Shehata W. Evaluation of engineering properties of scoria in central Harrat Rahat, Saudi Arabia. Bulletin of Engineering Geology and the Environment. 2000;59(3):219-25.

[27] Celik K, Jackson MD, Mancio M, Meral C, Emwas AH, Mehta PK, et al. High-volume natural volcanic pozzolan and limestone powder as partial replacements for portland cement in self-compacting and sustainable concrete. Cement and Concrete Composites. 2014;45(0):136-47.

[28] Moon J, Oh JE, Balonis M, Glasser FP, Clark SM, Monteiro PJ. High pressure study of low compressibility tetracalcium aluminum carbonate hydrates $3 \mathrm{CaO} \cdot \mathrm{Al}_{2} \mathrm{O}_{3} \cdot \mathrm{CaCO}_{3} \cdot 11 \mathrm{H}_{2} \mathrm{O}$. Cement and Concrete Research. 2012;42(1):105-10. 
[29] Moon J, Speziale S, Meral C, Kalkan B, Clark SM, Monteiro PJ. Determination of the elastic properties of amorphous materials: Case study of alkali-silica reaction gel. Cement and Concrete Research. 2013;54:55-60.

[30] Moon J, Yoon S, Wentzcovitch RM, Clark SM, Monteiro PJ. Elastic properties of tricalcium aluminate from high-pressure experiments and first-principles calculations| Macquarie University ResearchOnline. 2012.

[31] Moon J-h, Oh JE, Balonis M, Glasser FP, Clark SM, Monteiro PJ. Pressure induced reactions amongst calcium aluminate hydrate phases. Cement and Concrete Research. 2011;41(6):571-8.

[32] White CE, Provis JL, Bloomer B, Henson NJ, Page K. In situ X-ray pair distribution function analysis of geopolymer gel nanostructure formation kinetics. Phys Chem Chem Phys. 2013;15(22):8573-82.

[33] Soyer-Uzun S, Chae SR, Benmore CJ, Wenk HR, Monteiro PJ. Compositional Evolution of Calcium Silicate Hydrate (C-S-H) Structures by Total X-Ray Scattering. Journal of the American Ceramic Society. 2012;95(2):793-8.

[34] Kunz M, MacDowell AA, Caldwell WA, Cambie D, Celestre RS, Domning EE, et al. A beamline for high-pressure studies at the Advanced Light Source with a superconducting bending magnet as the source. Journal of synchrotron radiation. 2005;12(5):650-8.

[35] Lange DA, Jennings HM, Shah SP. Image analysis techniques for characterization of pore structure of cement-based materials. Cement and Concrete research. 1994;24(5):841-53.

[36] Yoon S, Oh S-g, Ha J, Monteiro PM. The effects of surface treatments on rapid chloride permeability tests. Materials Chemistry and Physics. 2012;135(2):699-708.

[37] Semmlow JL. Biosignal and medical image processing: CRC press; 2004.

[38] Escalante-García JI, Fuentes AF, Gorokhovsky A, Fraire-Luna PE, Mendoza-Suarez G. Hydration Products and Reactivity of Blast-Furnace Slag Activated by Various Alkalis. Journal of the American Ceramic Society. 2003;86(12):2148-53.

[39] Ben Haha M, Le Saout G, Winnefeld F, Lothenbach B. Influence of activator type on hydration kinetics, hydrate assemblage and microstructural development of alkali activated blast-furnace slags. Cement and Concrete Research. 2011;41(3):301-10.

[40] Bae S, Meral C, Oh J-e, Moon J, Kunz M, Monteiro PJ. Characterization of morphology and hydration products of high-volume fly ash paste by monochromatic scanning x-ray micro-diffraction ( $\mu$-SXRD).

Cement and Concrete Research. 2014;59:155-64.

[41] Chae SR, Moon J, Yoon S, Bae S, Levitz P, Winarski R, et al. Advanced nanoscale characterization of cement based materials using $\mathrm{x}$-ray synchrotron radiation: a review. International Journal of Concrete Structures and Materials. 2013;7(2):95-110.

[42] Oh JE, Moon J, Oh S-G, Clark SM, Monteiro PJ. Microstructural and compositional change of $\mathrm{NaOH}-$ activated high calcium fly ash by incorporating $\mathrm{Na}$-aluminate and co-existence of geopolymeric gel and C-S-H (I). Cement and Concrete Research. 2012;42(5):673-85.

[43] Querol X, Alastuey A, Fernández-Turiel J, López-Soler A. Synthesis of zeolites by alkaline activation of ferro-aluminous fly ash. Fuel. 1995;74(8):1226-31.

[44] Brough A, Katz A, Sun G-K, Struble L, Kirkpatrick R, Young J. Adiabatically cured, alkali-activated cement-based wasteforms containing high levels of fly ash: Formation of zeolites and Al-substituted CSH. Cement and concrete research. 2001;31(10):1437-47.

[45] Bakharev T. Geopolymeric materials prepared using Class F fly ash and elevated temperature curing. Cement and Concrete Research. 2005;35(6):1224-32.

[46] Ismail I, Bernal SA, Provis JL, Nicolas RS, Hamdan S, van Deventer JS. Modification of phase evolution in alkali-activated blast furnace slag by the incorporation of fly ash. Cement and Concrete Composites. 2013. 
[47] Criado M, Fernández-Jiménez A, Palomo A, Sobrados I, Sanz J. Effect of the $\mathrm{SiO}_{2} / \mathrm{Na}_{2} \mathrm{O}$ ratio on the alkali activation of fly ash. Part II: ${ }^{29}$ Si MAS-NMR Survey. Microporous and Mesoporous Materials.

2008;109(1):525-34.

[48] Stroncik NA, Schmincke H-U. Palagonite-a review. International Journal of Earth Sciences. 2002;91(4):680-97.

[49] Palomo A, Alonso S, Fernandez-Jiménez A, Sobrados I, Sanz J. Alkaline activation of fly ashes: NMR study of the reaction products. Journal of the American Ceramic Society. 2004;87(6):1141-5. 
Table 1. Chemical composition of natural pozzolan.

\begin{tabular}{lccccccccccc}
\hline Oxide & $\mathrm{Na}_{2} \mathrm{O}$ & $\mathrm{MgO}$ & $\mathrm{Al}_{2} \mathrm{O}_{3}$ & $\mathrm{SiO}_{2}$ & $\mathrm{P}_{2} \mathrm{O}_{5}$ & $\mathrm{~K}_{2} \mathrm{O}$ & $\mathrm{CaO}$ & $\mathrm{TiO}_{2}$ & $\mathrm{MnO}$ & $\mathrm{Fe}_{2} \mathrm{O}_{3}$ & LOI \\
\hline wt.\% & \multirow{2}{*}{3.39} & 8.73 & 14.74 & 46.48 & 0.629 & 1.27 & 8.78 & 2.31 & 0.19 & 12.16 & 1.324 \\
\hline
\end{tabular}

Table 2. Mixture proportions of activated samples $(\mathrm{s} / \mathrm{b}=0.45)$.

\begin{tabular}{ccccc}
\hline Label & $\begin{array}{c}\text { Natural } \\
\text { Pozzolan }\end{array}$ & $\begin{array}{c}\mathrm{NaOH} \\
\text { solution } \\
(\mathrm{g})\end{array}$ & $\begin{array}{c}\text { Sodium } \\
(10 \mathrm{M}, \mathrm{g})\end{array}$ & $\begin{array}{c}\text { Curing } \\
(\mathrm{Ms}=3.22, \mathrm{~g})\end{array}$ \\
\hline $\mathrm{NP}+\mathrm{SH}$ & 300 & 135 & 0 & $\left({ }^{\circ} \mathrm{C}\right)$ \\
$\mathrm{NP}+\mathrm{SH} / \mathrm{WG}$ & 300 & 108 & 27 & 80 \\
\hline
\end{tabular}

Table 3. Averaged atomic compositions (\%) on selected matrices as determined by SEM-EDS analysis.

\begin{tabular}{ccc}
\hline Atomic $\%$ & NP-SH & NP-SH/WG \\
\hline $\mathrm{O}$ & 49.6 & 49.0 \\
$\mathrm{Na}$ & 7.1 & 9.0 \\
$\mathrm{Mg}$ & 2.8 & 2.2 \\
$\mathrm{Al}$ & 9.3 & 9.7 \\
$\mathrm{Si}$ & 18.7 & 22.5 \\
$\mathrm{~K}$ & 1.0 & 1.1 \\
$\mathrm{Ca}$ & 5.0 & 3.4 \\
$\mathrm{Ti}$ & 1.1 & 0.8 \\
$\mathrm{Fe}$ & 3.5 & 3.6 \\
\hline
\end{tabular}




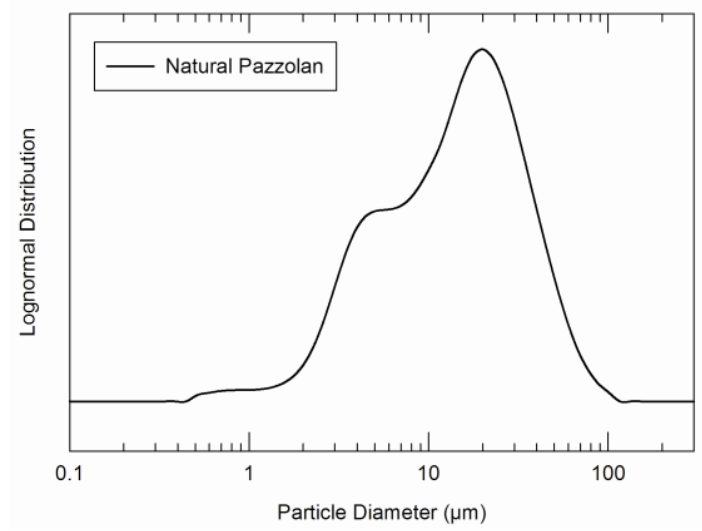

Figure 1. Particle size distribution of natural pozzolan.

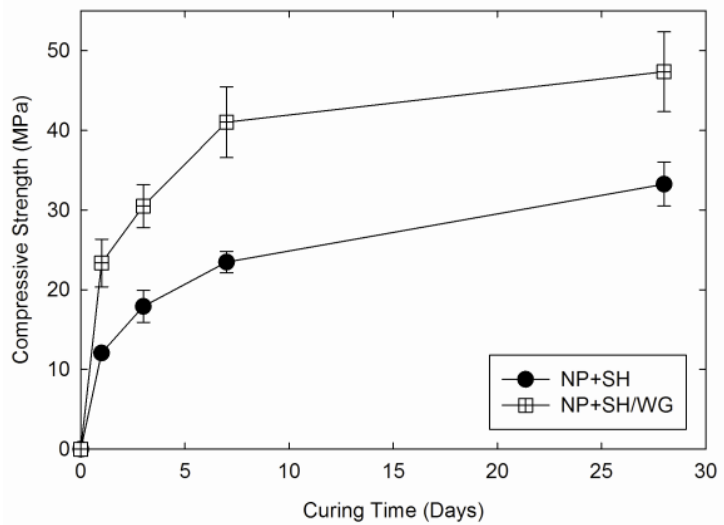

Figure 2. Strength development of alkali-activated natural pozzolan. 


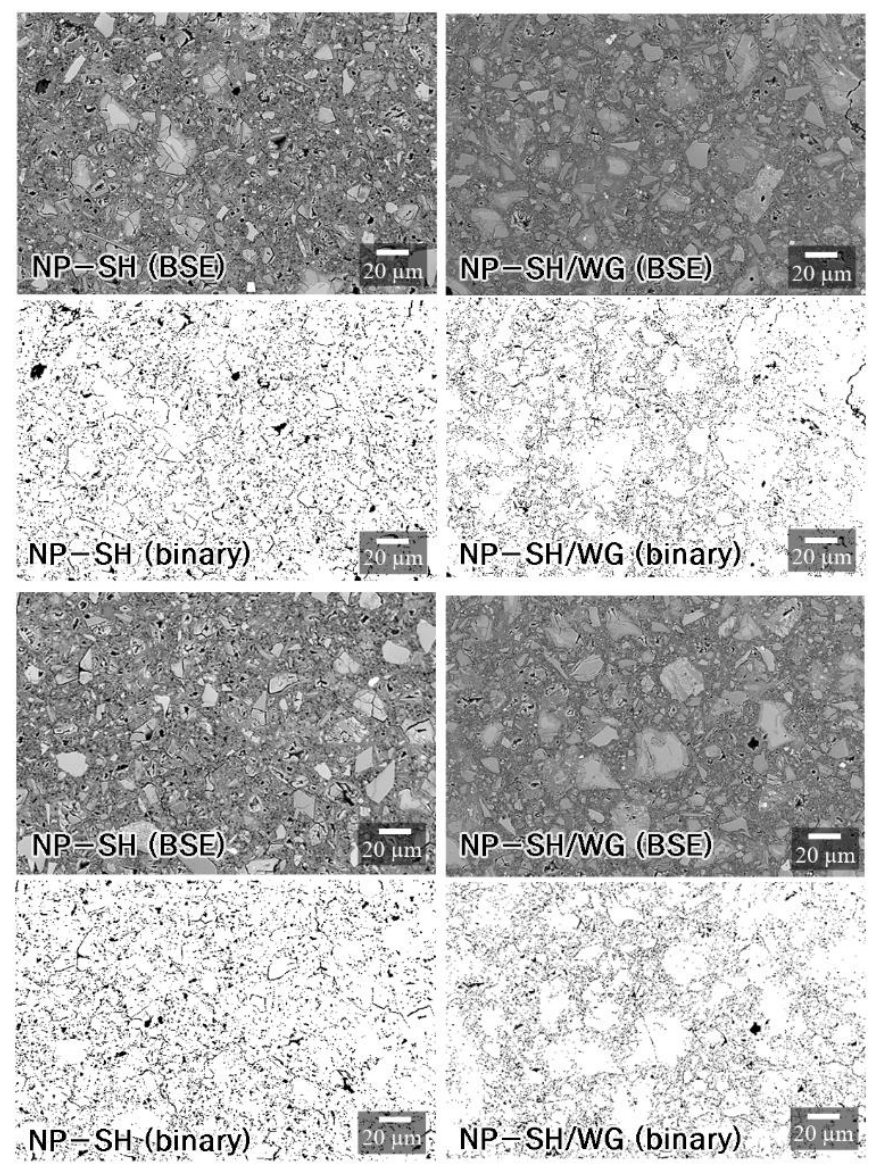

Figure 3. Typical microstructures of $\mathrm{NP}+\mathrm{SH}$ and $\mathrm{NP}+\mathrm{SH} / \mathrm{WG}$ samples. Each bottom image shows microsize porosity (pores are displayed in black).

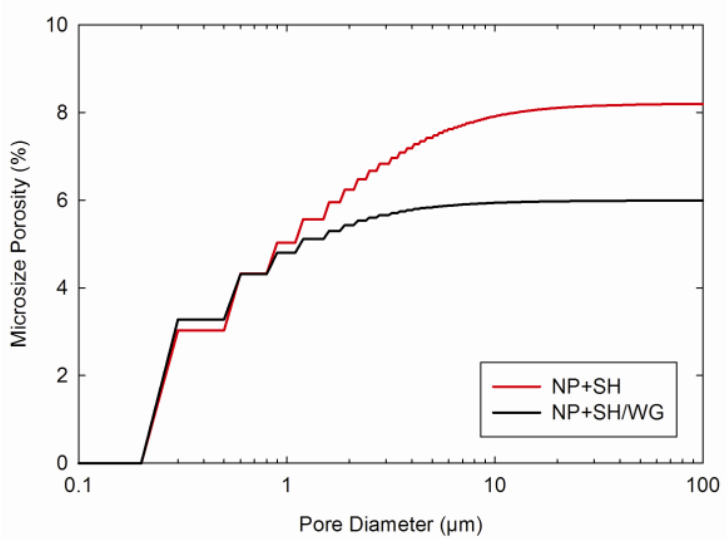

Figure 4. Micro-size porosity distribution obtained from BSE image analysis. 

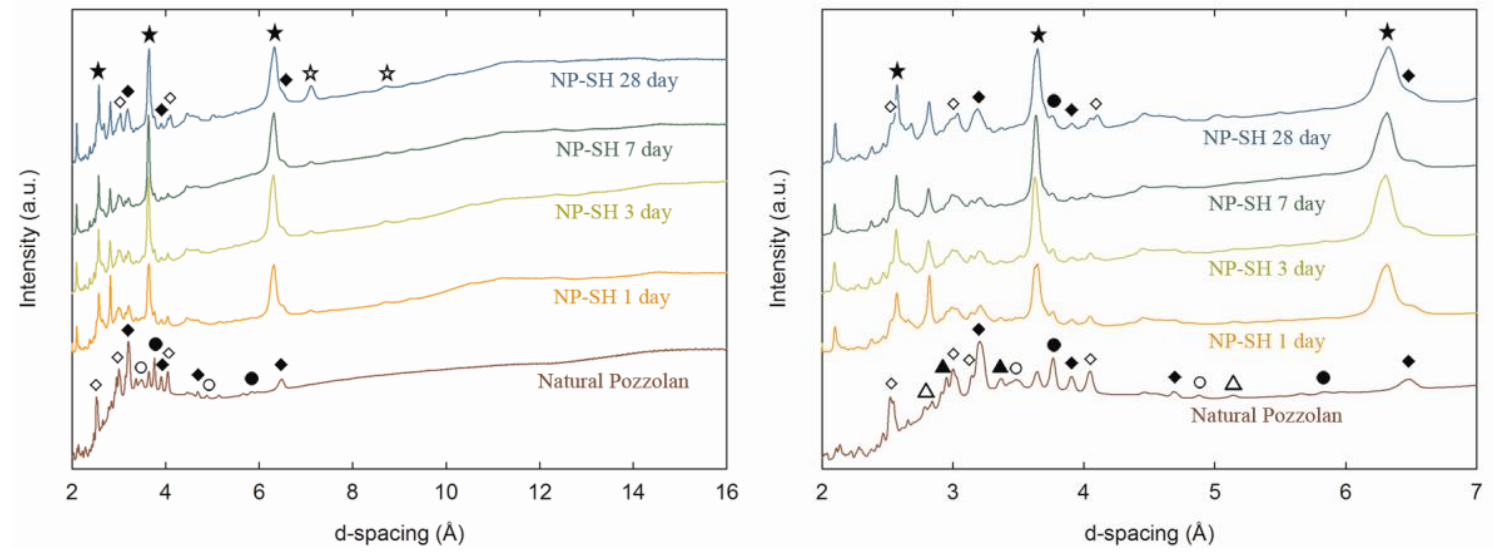

Figure 5. High-resolution X-ray diffraction patterns of basaltic pozzolan and NP-SH samples, cured for 1, 3, 7, and 28 days. Anorthite (black diamond), maghemite (black circle), forsterite (white triangle), brookite (white circle), cristobalite alpha (white diamond), and diopside (black triangle) were found in raw material. Activation products of hydroxysodalite (black star) and zeolite Y (white star) were found with unreacted crystals of anorthite, cristobalite alpha, and maghemite.
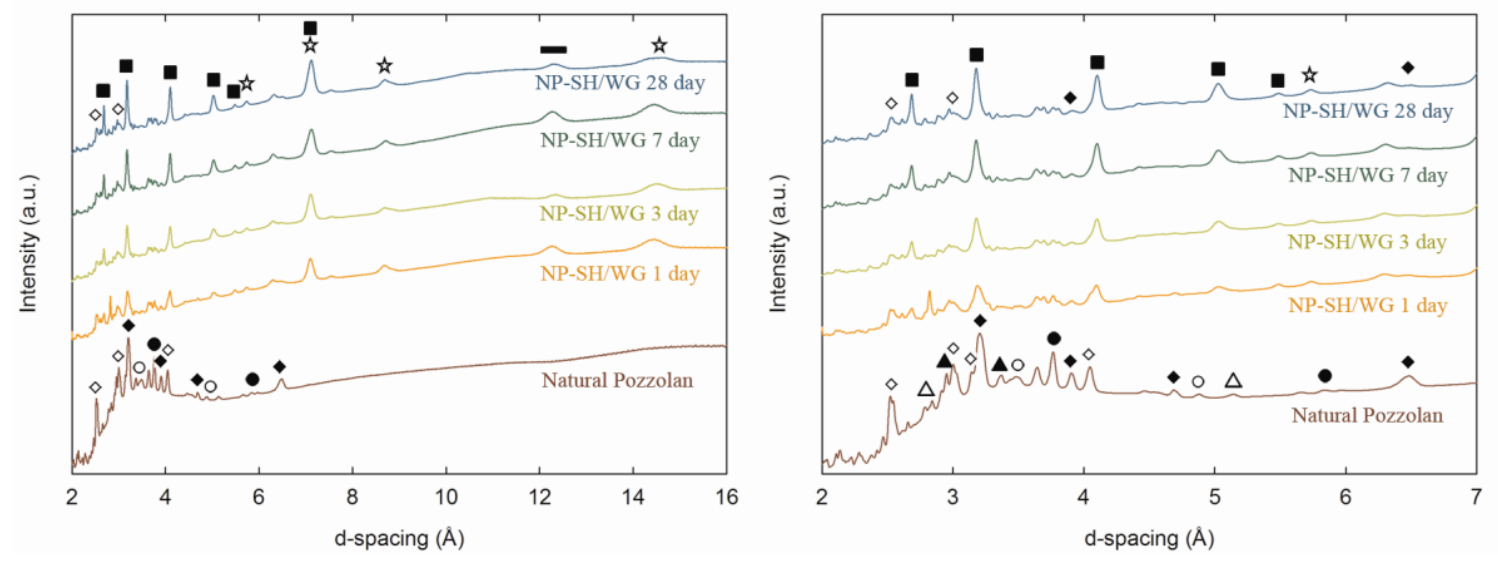

Figure 6. High-resolution X-ray diffraction patterns of basaltic pozzolan and NP-SH/WG samples, cured for 1, 3, 7, and 28 days. Identical symbol notation in Fig. 6 is used. New activation products of phillipsite (black rectangular) and C-S-H (black bar) were found with zeolite Y (white star). 


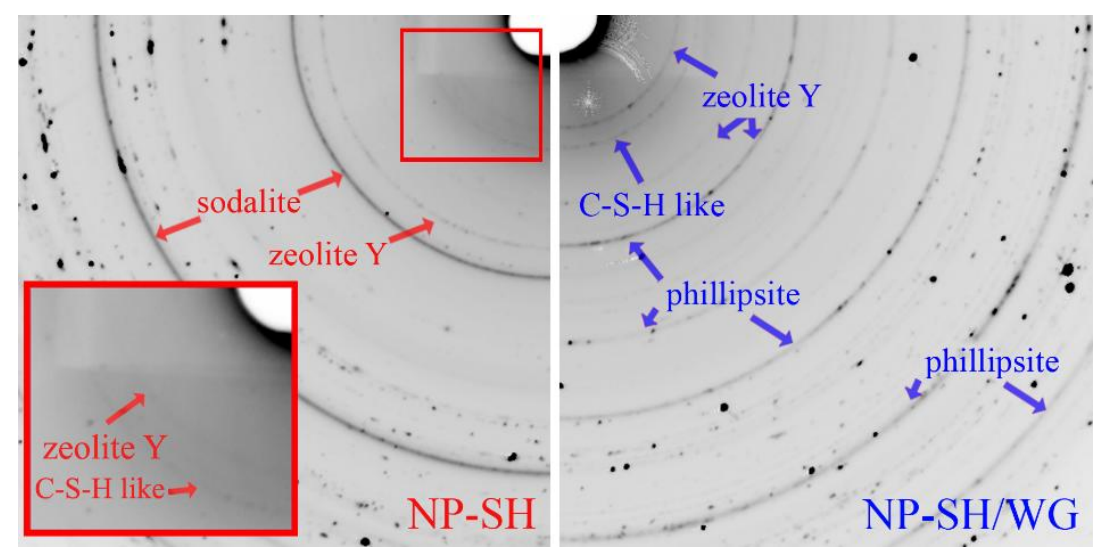

Figure 7. 2-dimensional powder diffraction patterns of NP-SH (left) and NP-SH/WG (right).

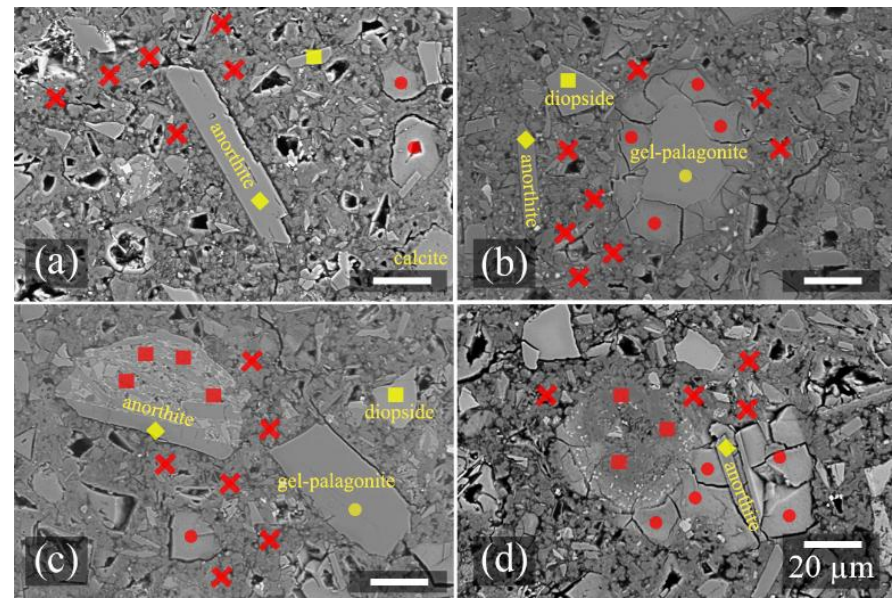

Figure 8. Microstructure of NP-SH sample. Raw crystals in natural pozzolan and newly activated crystals are shown in yellow and red, respectively. 


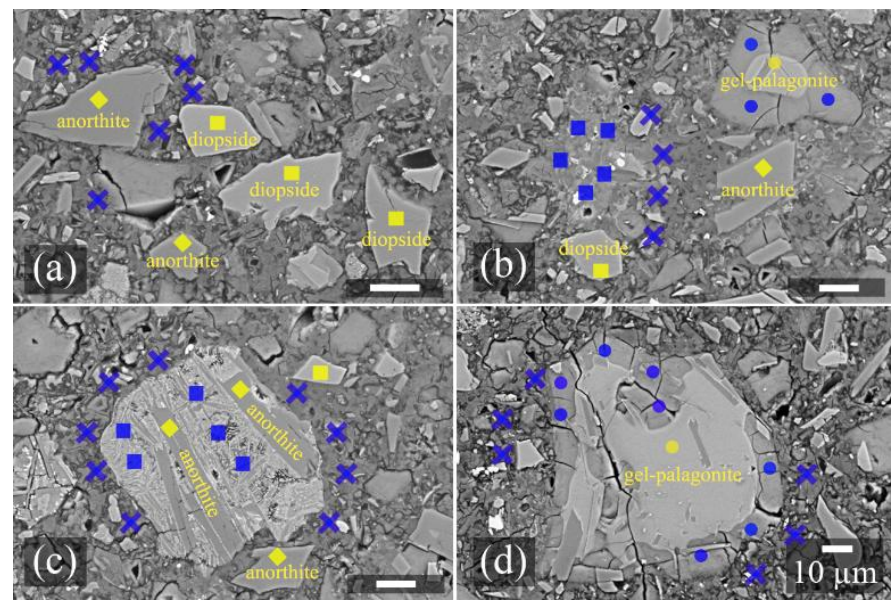

Figure 9. Microstructure of NP-SH/WG sample. Raw crystals in natural pozzolan and newly activated crystals are shown in yellow and blue, respectively.

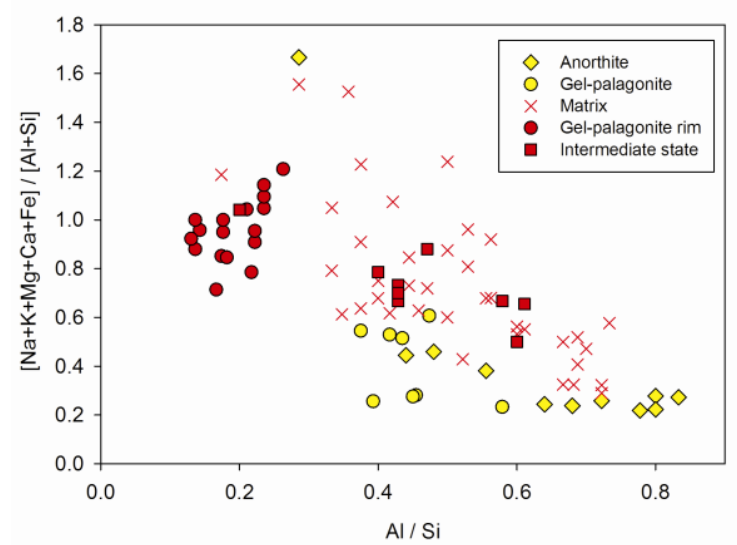

Figure 10. Compositional analysis of natural pozzolan activated with $\mathrm{NaOH}$. The symbols correspond to the selected locations in Fig. 8 for EDS spot analysis. 


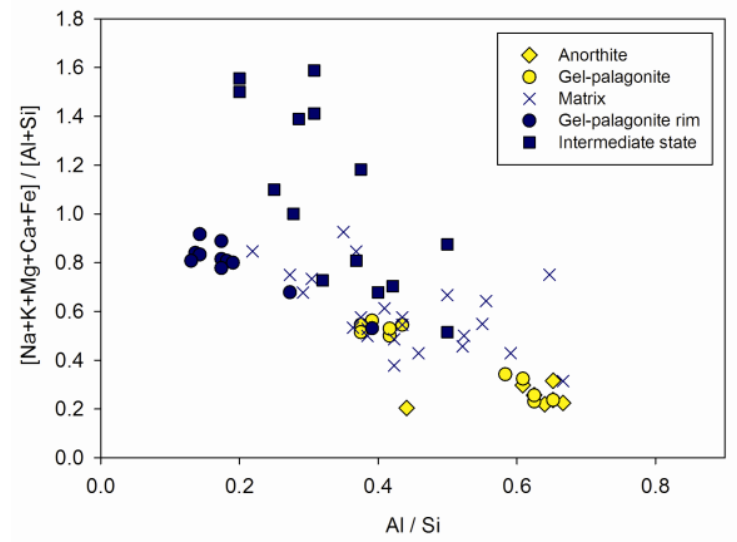

Figure 11. Compositional analysis of natural pozzolan activated with a mixture of $\mathrm{NaOH}$ and waterglass. The symbols correspond to the selected locations in Fig. 9 for EDS spot analysis.

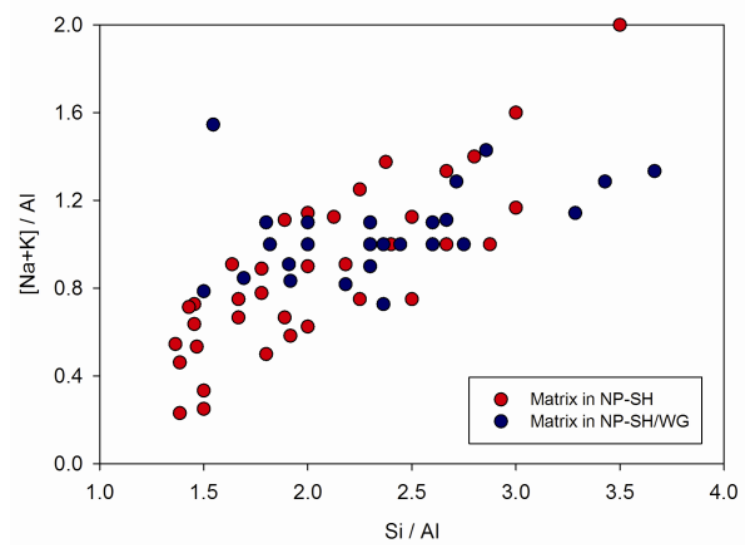

Figure 12. Comparison of atomic ratio of matrices in NP-SH and NP-SH/WG. 